\title{
ANÁLISE DE REDES SOCIAIS NO ARRANJO PRODUTIVO LOCAL DOS RAMOS TÊXTIL E DE CONFECÇÕES DA REGIÃO DA GRANDE SÃO PAULO A PARTIR DE UMA VISÃO DE GOVERNANÇA \\ SOCIAL NETWORK ANALYSIS IN CLUSTER OF THE TEXTILE AND CLOTHING INDUSTRY FROM THE GREATER SÃO PAULO REGION, BRAZIL, WITH A GOVERNANCE POINT OF VIEW
}

\section{Milton Carlos Farina}

Doutor em Administração pela Faculdade de Economia, Administração e Contabilidade da Universidade de São Paulo, professor do curso de mestrado e doutorado da Universidade Municipal de São Caetano do Sul, São Caetano do Sul (SP), Brasil

Data de recebimento: 23-12-2015

Data de aceite: 13-10-2016

\section{Alessandra Preto Bitante \\ Doutoranda em Administração pela Universidade Municipal de São Caetano do Sul, São \\ Caetano do Sul (SP), Brasil}

\section{Lidiane Campos Brito}

Doutoranda em Administração pela Universidade Municipal de São Caetano do Sul, São

Caetano do Sul (SP), Brasil

\section{Luciane Ribeiro Dias Pinheiro}

Doutoranda em Administração pela Universidade Municipal de São Caetano do Sul, São

Caetano do Sul (SP), Brasil

\section{RESUMO}

Este artigo caracteriza-se pelo estudo das relações entre os atores participantes do Arranjo Produtivo Local (APL) têxtil e de confecções situado na região da Grande São Paulo a partir de uma visão de governança. Para compreender os fatores facilitadores e dificultadores das relações no arranjo, foi feito um levantamento bibliográfico sobre os temas. Foram entrevistados representantes do sindicato do setor têxtil e de confecções, da prefeitura local e de uma universidade colaboradora do aglomerado. Além disso, 26 empresas pertencentes ao APL responderam a um questionário estruturado e, por fim, assistiu-se uma reunião do arranjo em junho de 2015. A principal conclusão deste artigo é que ainda há mais fatores dificultadores que facilitadores para o sucesso do APL estudado, como a pouca adesão/participação das empresas do setor e a escassez de mão de obra especializada no setor.

Palavras-chave: Análise de redes sociais; APL; governança.

\section{ABSTRACT}

This article is characterized by the study of the relationships between the actors participants of the Textile and Clothing Local Productive Arrangement in the Greater São Paulo region from a point of view focused on governance. To understand the facilitating and hindering factors of relationships in a cluster, a bibliographical survey on those topics was carried on. The interviews were conducted with union representative of the textile industry, from the local municipality and a collaborator from one local university. Additionally, 26 companies from the cluster answered to a structured survey and, at last, a cluster meeting was observed in June 2015. The main conclusion of this study is that there are still more hindering factors than facilitating so that the cluster studied can succeed. These include the companies' lack of aid/participation from the local sector productive arrangement and the shortage of skilled labor.

Keywords: Social network analysis; cluster; governance. 


\section{INTRODUÇÃO}

O objetivo deste artigo é identificar os principais fatores facilitadores e dificultadores das relações entre os atores participantes do Arranjo Produtivo Local (APL) têxtil e de confecções situado na região da Grande São Paulo a partir de uma visão de governança.

O conceito de aglomeração está diretamente relacionado à competividade que, por sua vez, é um dos fatores primordiais para o crescimento e a inovação das empresas. Dessa forma, entender questões concernentes ao tema aglomerações, que passa a ficar mais evidente a partir de 1990, é relevante para a compreensão das relações competitivas entre as empresas de um mesmo setor (CASSIOLATO; SZAPIRO, 2003). A competitividade e o crescimento, de forma geral, ocorrem com mais frequência no mundo globalizado quando as empresas se juntam em aglomerações como os APLs, o que resulta no aumento de renda da comunidade (ZACCARELLI et al., 2008; CASSANEGO, 2014).

Para Olson (1999), a cooperação é o principal aspecto a ser considerado para a evolução e sobrevivência de um APL - ou aglomeração - já que, quando as empresas cooperam e trabalham juntas, as dificuldades são superadas e o risco de conflitos é reduzido. Dessa maneira, as empresas aprendem juntas, têm acesso a ganhos e muitas outras vantagens.

Ressalta-se que o catalisador de um arranjo pode estar estruturado não apenas em princípios de competitividade, mas de integração entre os atores que formam uma rede de parceiros, compartilhando recursos, capacitações e experiências. Por estratégias de cooperação, entende-se "estratégias em que as empresas trabalham juntas para atingirem um objetivo" (HITT; IRELAND, HOSKISSON, 2013, p. 246). Assim, com base no conceito de $A P L$, percebe-se que o fator governança tende a ser determinante nas relações entre as empresas à medida que possibilita e desenvolve práticas que fomentam uma ligação entre elas, trazendo à estrutura questões relativas à competitividade, à cooperação, à geração de valor e às políticas públicas.

De acordo com Schmitz e Nadvi (1999), assim como os APLs, o conceito de cluster diz respeito a uma concentração espacial e setorial de empresas que estão conectadas localmente para juntas competirem melhor em mercados nacionais e internacionais.

Segundo Macedo, Araújo e Campos (2014), a designação de cluster é frequente em artigos acadêmicos, além de também ser usado por entidades governamentais e apoiadores de projetos dessa natureza. O termo "APL", por sua vez, é muito utilizado pelo Ministério do Desenvolvimento, Indústria e Comércio Exterior (MDIC), pelo Serviço Brasileiro de Apoio às Micro e Pequenas Empresas (Sebrae) e pelo Consórcio Intermunicipal.

Para fins conceituais, neste trabalho, as denominações cluster, APL, aglomerados e aglomerações serão consideradas sinônimas, já que o artigo tem como objeto central, o APL têxtil e de confecções, formado por empresas do mesmo setor e em uma região delimitada.

Sacomano Neto e Paulillo (2012, p. 1131) pontuam que a "governança nos arranjos produtivos se refere ao modo de coordenação, comando, intervenção e participação dos atores do arranjo". Acrescentam que a compreensão do elemento governança em um aglomerado tem gerado interesse no Estado, que pode responder a esse fator por meio de mudanças em suas políticas públicas.

É importante frisar que, para verificar os fatores que facilitam e que dificultam as relações entre os atores participantes do APL nas questões de governança, pode-se considerar suas relações sociais por meio da análise de redes sociais (ARS). O objetivo deste trabalho é indicar e analisar esses fatores.

O conceito de rede de acordo com Newman (2010) é um conjunto de nós que estão 
interligados em pares por linhas. As análises das relações (linhas) entre esses nós geram informações sobre os fenômenos, ou seja, as relações exercem influência sobre a própria rede e entendê-las auxilia na resolução de problemas e conflitos, como também na potencialização de suas vantagens.

Este trabalho encontra-se estruturado da seguinte forma: introdução, referencial teórico, delineamento metodológico da pesquisa, análise dos resultados, conclusão e referências utilizadas.

\section{REFERENCIAL TEÓRICO}

No referencial teórico a seguir, foram levantados aspectos que reúnem o entendimento concomitante dos conceitos de ARS, APLs e de governança.

\subsection{APLS}

Porter (1998) afirma que as localizações das empresas geram vantagens competitivas para as aglomerações, que são formadas por facilidade de acesso à mão de obra qualificada e matéria-prima, como também aos clientes, o que traz vantagens em relação às empresas que atuam sozinhas (ZACCARELLI et al., 2008).

O desenvolvimento das economias locais apresenta aumento da especialização da atividade, o que resulta em vantagens e desenvolvimento regional e local que favorecem as comunidades (BRITO, 2002; COSTA, 2001). As empresas que formam esses aglomerados podem ser de vários tamanhos, mas a maioria é de pequenas e médias empresas, que buscam nestes arranjos superar as dificuldades existentes em um caminho isolado.

Para Antero et al. (2016), a coordenação de um APL consiste de vários fatores como formalidade, integração de todos, maior participação nas tarefas em conjunto, modo de gestão e de condução.
Devido à troca de conhecimentos e informações, um aglomerado tem benefícios gerados da negociação coletiva de componentes e insumos, na redução de custos de produção e, em um nível maior de qualidade e de especialização, melhor prestação de serviço, qualificação de mão de obra, consórcio para venda de bens e serviços, entre outros (SANTOS et al., 2003).

As aglomerações empresariais resultam em novos conhecimentos e inovações que podem estimular a competição (LASTRES; CASSIOLATO, 2003; MACEDO; ARAÚJO; CAMPOS, 2014; AMARAL, 2013). Por sua vez, a literatura aponta que os clusters têm como características: mobilidade e qualificação de trabalhadores, confiança entre os atores participantes do arranjo, contato pessoal, fornecedores especializados, que só ocorrem pela proximidade geográfica, como também fortes relações entre as empresas, associações de comércio, instituições de apoio, como o governo e instituições de ensino. Esses arranjos apresentam coordenação e cooperação, bem como competição (TOLEDO; GUIMARÃES, 2008; DONAIRE et al. 2013). Assim, as empresas criam estratégias baseadas nas vantagens e benefícios de se fazer parte de um arranjo que, embora competindo entre si, também se complementam para conquistar mercados e realizar negócios (GUIMARÃES, 2010).

Guimarães et al. (2013) ainda apontam os benefícios da formação dos arranjos que são facilitam a participação de feiras tecnológicas, a redução de custo logístico e a capacitação gerencial e tecnológica com outras empresas. Esses fatores, de forma geral, poderiam, portanto, ser configurados como facilitadores para o sucesso de empresas pertencentes a APLs.

A conexão eficaz e eficiente entre os atores participantes de uma entidade dessa natureza é que resultam em uma sustentabilidade da cadeia produtiva e a organização e coordenação resultam em um desenvolvimento coletivo regional e local que dão origem a um aglomerado (LÜBECK; WITTMANN; SILVA, 2012). 
Teixeira (2009) afirma que os APLs possuem em sua formação atores econômicos, institucionais, sociais, políticos e empresarias que juntos trabalham para realizar ações e atividades produtivas conjuntas, visando um objetivo coletivo.

As empresas que fazem parte do arranjo não devem apenas considerar suas individualidades, mas também as necessidades e atividades coletivas do APL e, a partir disso, depreende-se a noção de rede, que são as complexas conexões com objetivo de compartilhamento entre instituições e empresas, o que é um dos mais importantes fatores para o nascimento, a evolução e o desenvolvimento dos APLs, em que a participação, cooperação e confiança formam a base desses arranjos (WITTMANN; RAMOS, 2004).

Patias et al. (2015) pontuam que buscar vantagens competitivas sustentáveis é uma prática para a sobrevivência em cenários econômicos dinâmicos. Nesse sentido, os APLs são uma alternativa viável que tendem a combinar, em suas estratégias, competição e cooperação.

Os aglomerados podem ter concentração de atividades similares ou que são dependentes no espaço. As empresas que formam o arranjo podem ser de qualquer tamanho e ter qualquer atividade econômica, pertencendo a qualquer setor como o primário, secundário ou o terciário, podendo ser composto de empresas artesanais ou até de alta tecnologia, além de que pode possuir uma cadeia produtiva local, regional, nacional ou até internacional (ZACCARELLI et al., 2008).

Uma vez que as relações nem sempre apresentam uniformidade, além de ocorrer alguns conflitos, há necessidade de articulação entre os atores envolvidos no APL. Essa articulação pode ser realizada por uma ou várias instituições, como o governo, sindicatos, associações etc., e que recebe a denominação de governança.

Por sua importância no desenvolvimento econômico, regional e das empresas, de acordo com Oliveira e Santana (2016); Macedo, Araújo e Campos (2014); Masquietto, Sacomano Neto e Giuliani (2010), o número de estudos sobre APLs tem aumentado na literatura acadêmica. Sousa et al. (2015) colocam ainda que, devido à importância do tema, diversos trabalhos já foram feitos para o entendimento da cooperação e competição em um APL, configurado como um ambiente de rede.

\subsection{Governança em APLs}

A discussão integrada relativa aos conceitos de APL e de governança tornou-se mais evidente há alguns anos no Brasil (VILLELA; PINTO, 2009), devido não apenas às questões políticas e econômicas, mas também ao entendimento de que alianças estratégicas, quando bem concebidas e permeadas por um sistema de governança efetivo, podem gerar vantagens competitivas aos participantes por meio da cooperação.

Para Costa e Rabelo (2013), governança é um conceito amplo e, por isso, é importante defini-lo a partir do tema em que esteja sendo aplicado. Dessa forma, a definição de governança para este trabaIho está diretamente associada às questões relativas aos APLs.

Os autores Sacomano Neto e Paulillo (2012, p. 1133) destacam que "o desenvolvimento de um APL depende fortemente dos atores e suas relações de poder". Relações estas que podem formar uma rede extensa de parceiros dos mais diversos tipos e não necessariamente restritos por questões territoriais. Por sua vez, para Antero et al. (2016), a proximidade dos atores de um APL, devido às questões espaciais, pode, muitas vezes, resultar em relações mais estreitas entre as empresas e as organizações participantes, facilitando, desta forma, ações conjuntas para objetivos comuns. Villela e Pinto (2009, p. 1068) endossam que "governança é o processo de coordenação de atores, grupos sociais, instituições ou redes empresariais para alcançar objetivos discutidos e definidos coletivamente". 
À medida que o Estado percebe que, em prol do bem comum e da qualidade de vida, é preciso uma gerência profícua de redes das organizações privadas e do terceiro setor por meio de políticas públicas, surge uma nova configuração de gestão organizacional (CRUZ; MARTINS; QUANDT, 2008). Esta nova configuração proporciona aos atores possibilidades de interações estimuladas por sistemas sociais muitas vezes informais, resultando em prováveis mecanismos que aumentem a comunicação entre os pares, elevando o nível de confiança uns nos outros e, por consequência, possibilitando maior transferência de conhecimento entre os atores (Ibidem, 2008). Macedo, Araújo e Campos (2014) afirmam ainda que a junção de esforços entre o Estado e as empresas podem trazer benefícios recíprocos.

Em contrapartida, Villela e Pinto (2009) afirmam que, pelo Estado deixar lacunas nos mais diversos níveis relativos às questões sociais (não apenas no Brasil, mas em diversas partes do mundo), os APLs surgem como uma solução possível para os atores envolvidos. Asseguram ainda que, no locus em que normalmente surgem os APLs, não por coincidência, existem pessoas que possuem conhecimento e capacitações essenciais para tornar o APL possível, o que configura, na teoria, um sistema de governança, a priori, informal, mas capaz de mobilizar a coletividade, ainda que nem sempre os interesses sejam totalmente convergentes.

Villela e Pinto (2009) e Macedo, Araújo e Campos (2014) colocam ainda que o impacto socioeconômico causado por um APL pode atrair atores coadjuvantes do processo, como instituições de ensino, sindicatos, associações etc. Por sua vez, sabe-se que um dos fatores dificultadores do processo é alinhar os interesses comuns de todas as organizações, visto que, a partir da configuração de um APL com uma rede mais complexa e com organizações dos mais diversos formatos e tamanhos, há objetivos que nem sempre são comuns a todos, assim o estudo das relações sociais por meio de
ARS entre esses atores se faz essencial para caracterizar os fatores que facilitam ou dificultam essas relações.

\subsection{ARS}

Marteleto (2001) afirma que, de forma geral, nos estudos sobre redes sociais, a literatura não aponta uma "teoria de redes sociais", mas que o conceito pode ser utilizado em diferentes questões sociais.

Para Ruffoni e Suzigan (2015), a ARS, em inglês, social network analysis (SNA), é uma metodologia que pode ser utilizada em diversas áreas do conhecimento, entre elas, a administração. Devido aos contínuos estudos a respeito dessa metodologia, em sua aplicabilidade podem ser empregadas diversas representações matemáticas, gráficas e estatísticas, diferenciando, assim, as mais variadas formas de redes. Ainda para os autores, a adoção do tipo de rede e dos indicadores mais importantes, depende do objetivo do estudo a ser feito.

Segundo Castells (1999), o mundo vive em uma sociedade em rede. Por esta razão, faz-se necessária a ARS, que, por sua vez, teve uma de suas origens, de acordo com Mizruchi (2006), na psicologia por meio dos trabalhos realizados por Moreno (1934). Este autor desenvolveu um estudo em que as relações interpessoais eram representadas graficamente.

Outra origem possível da ARS, apontada por Wellman (1988) apud Mizruchi (2006), é na sociologia estrutural, que estuda as estruturas sociais, restrições e oportunidades que atingem mais 0 comportamento humano do que as regras determinadas pela sociedade. Entende-se, assim, que a ARS é um tipo de sociologia estrutural que analisa os efeitos das relações sociais sobre o comportamento individual.

Para Santos, Rossoni e Machado-da-Silva (2011), a ARS, ainda como um de seus objetivos, 
pode verificar, no campo dos estudos organizacionais, a complexidade das relações existentes nas organizações, sua intensidade, direção e até mesmo as implicações da combinação relacional de seus atores. No entanto, ainda que esse tema se revele atraente, para este trabalho, o foco será a relação entre as organizações.

A ARS tem como objetivo mensurar e mapear as conexões entre os participantes de um grupo, como em um APL, a fim de evidenciar suas relações sociais de forma gráfica (KNOKE; YANG, 2008). As bases utilizadas pela ARS são a Teoria dos Grafos e a Estatística (PARKHE; WASSERMAN; RALSTON, 2006).

De acordo com Pigatto; Queiroz e Lourenzani (2015), para o entendimento mais profundo de estudos em segmentos específicos, a abordagem de redes pode também auxiliar as pesquisas mais voltadas às questões econômicas e de eficiência produtiva, complementando-as. Este é o caso, por exemplo, deste artigo, no qual o foco é o setor têxtil e de confecções situado na região da Grande São Paulo.

A ARS conta com as ferramentas da estatística que disponibiliza dois tipos de medidas: as descritivas e as de análise estrutural. Todavia, para este estudo serão utilizados alguns itens da medida descritiva a seguir:

- Densidade (density): para Scott (2009), essa medida aponta a intensidade das relações da rede. Quanto maior a conexão de pontos uns com os outros, maior será a densidade;

- Centralidade de grau (degree): para Wasserman e Faust (1999), indica que o ator que possui alta centralidade apresenta maior visibilidade e se encontra, de forma direta, conectado a outros atores, ou seja, tem uma participação importante sobre os resultados coletivos;

- Centralidade de proximidade (closeness): mede a distância que um ator está dos outros. Ou seja, demonstra a média de proximidade de cada ator em relação aos demais (WASSERMAN; FAUST, 1999);

- Centralidade de intermediação (betweeness): mensura o grau de intervenção que um par de atores exerce sobre outro ator. Isso demonstra que para ter uma alta intermediação, é necessário haver interação entre atores não próximos por meio de outro ator (WASSERMAN; FAUST, 1999).

Dessa maneira, percebe-se que ARS é um estudo que observa as relações entre os atores e sua interação. Por esta razão, as medidas já citadas neste artigo são utilizadas para estudar a menor estrutura de relação que há entre dois atores (díades). Também pode-se estudar as tríades, isto é, a relação entre três atores, cujo objetivo é analisar um ator em relação aos outros atores da tríade (HANNEMAN; RIDDLE, 2005).

Pigatto; Queiroz e Lourenzani (2015) apontam ainda que a transferência de conhecimento (em inglês, knowledge transfer) é uma das possibilidades de vantagens apontadas pelo conhecimento que se tem da coesão da rede e da proximidade de seus atores.

Nesta pesquisa, serão estudadas as relações entre atores com a perspectiva de analisar a governança na rede de empresas que fazem parte do APL têxtil e de confecções situado na Grande São Paulo.

\section{PROCEDIMENTOS METODOLÓGICOS}

O trabalho objetiva identificar os principais fatores facilitadores e dificultadores das relações entre os atores participantes do APL têxtil e de confecções da Grande São Paulo a partir de uma visão de governança. Dessa forma, a pesquisa é exploratória e de caráter descritivo (GIL, 2002). A indicação desses fatores no APL têxtil e de confecções pode contribuir para estudos em APLs de outros setores e para a literatura acadêmica. Para alcançar o 
objetivo deste trabalho, utilizou-se de entrevistas semiestruturadas, com roteiro de perguntas abertas realizadas com três entidades representadas por um membro do sindicato do setor, um membro de uma instituição de educação superior envolvida com o APL e um representante da prefeitura local que coordena as ações do APL pesquisado. A amostra foi escolhida por acessibilidade. Além das entrevistas, utilizou-se da observação por meio da participação em uma das reuniões das empresas do APL, em junho de 2015, e da aplicação, via telefone e presencialmente, de um instrumento estruturado denominado questionário. O questionário aplicado é composto por três partes: a primeira diz respeito ao perfil da empresa, inclusive, os principais produtos comercializados por cada uma delas; a segunda parte trata das perguntas relativas à ARS, nas quais cada empresa responde sobre sua relação de negócios, ajuda/colaboração com cada uma das outras empresas participantes do APL; e, por fim, a última parte trata de uma pergunta aberta: "na sua opinião qual a principal dificuldade enfrentada pelo APL têxtil e de confecção do qual você participa?"

A relação das empresas pesquisadas foi fornecida pela coordenadora do APL têxtil e de confecções, a qual, na época da coleta de dados, era funcionária da prefeitura de uma das cidades participantes do APL. No total, são 40 participantes do $A P L$, sendo que 26 dessas empresas responderam ao questionário.

Assim, com base na descrição da metodologia empregada, a pesquisa deste trabalho se caracteriza tanto qualitativa quanto quantitativa. Isto é, uma metodologia mista associada às duas formas de coleta e análise de dados (CRESWELL, 2007). Com relação ao procedimento utilizado pela ARS, foram utilizadas algumas medidas, como a densidade da rede, por indicar o quanto as empresas fazem negócios entre si. Por exemplo, se a densidade é baixa, isto significa que poucos negócios são realizados em conjunto e no caso da ajuda/ colaboração entre as empresas, enquanto caso a densidade da rede seja alta, isto significa que as empresas se ajudam mutuamente. Para a análise de cada ator da rede, a medida de centralidade de grau (degree) indicará as empresas com alto valor de degree; o que significa que ela faz negócios com muitas empresas, por pertencer ao APL e que ajuda ou tem colaboração de muitas empresas e vice-versa.

A medida de centralidade de proximidade (closeness) com valores altos indica que as empresas não são próximas entre si, isto é, a empresa A se relaciona diretamente com poucas empresas e de forma indireta (por meio de outras empresas) com muitas empresas do APL.

A medida de centralidade (betweeness) indica o grau de intermediação que uma empresa tem com relação a pares de empresas da rede. Por exemplo, um alto grau de intermediação indica que aquela empresa é importante para a rede. As empresas podem fazer negócios com outras por meio dela.

Com base nas medidas fornecidas pela ARS, pela observação e pelas entrevistas, este trabalho apresentará os fatores que dificultam e que facilitam as relações entre as empresas, o que, por sua vez, deverá indicar o estágio atual da governança do APL.

\section{ANÁLISE DOS RESULTADOS}

A análise dos resultados apresentada a seguir está fundamentada na metodologia para responder os objetivos destacados nesta pesquisa e com base nas teorias expostas no referencial teórico, iniciando pela identificação dos fatores facilitadores e dificultadores das relações entre as empresas que fazem parte do APL têxtil e de confecções situado na Grande São Paulo e por como essas mesmas empresas fazem negócios em conjunto e cooperam entre si. Segundo Schmitz e Nadvi (1999), a união das empresas faz com que a cooperação seja maior. 
Este aspecto foi destacado na entrevista com o representante do sindicato têxtil quando afirmado que a união representa segurança para os empresários e que isso facilita também a questão de compras coletivas, fator também apontado por Santos et al. (2003) quando aborda sobre as vantagens das conexões econômicas entre os atores participantes de um arranjo.

Assim, para responder o objetivo principal deste artigo que é o de identificar os fatores facilitadores e dificultadores das relações entre as empresas, buscou-se entender de que forma as empresas fizeram ou fazem negócios umas com as outras. Para isso, além das análises qualitativas, utilizou-se também o software Ucinet conforme a Figura 1:

Nas figuras 1 e 2, a partir da análise do questionário, optou-se por representar as 26 empresas em cores. Desta forma, cada uma das dez cores a seguir diz respeito a uma categoria do produto principal de comercialização das empresas. Roupas femininas: cor preta; roupas masculinas: cinza claro; roupas infantis: lilás; uniformes: vermelho; acessórios: cinza escuro; locação de roupas: marrom; moda praia: azul claro; roupas femininas/infantil: amarelo; lingerie: azul escuro; equipamentos de proteção individual: verde claro; e bordado: verde escuro.

Na Figura 1, as 26 empresas fazem parte da rede de negócios do APL têxtil e de confecções situado na região da Grande São Paulo por meio de negócios realizados entre elas mesmas. Esta ação é destacada por Santos et al. (2003) como um dos aspectos de um APL. Ainda de acordo com Guimarães (2010), as organizações, por fazerem parte de grupos dessa natureza, elaboram estratégias de cooperação, mesmo também competindo entre si, com o objetivo de conquistar mercados e realizar negócios.

Observa-se na ARS da Figura 1 que as empresas $3,4,8,9,12,13,14$ e 19 se destacam como empresas que fizeram negócios com outras empresas por meio de sua participação no APL têxtil e de confecções. Entretanto, as empresas 1, 5, 6, 10, 17 , 21 e 23 não fizeram negócios com outras empresas do APL. Retomando o referencial teórico, uma conexão profícua entre os atores participantes de um APL

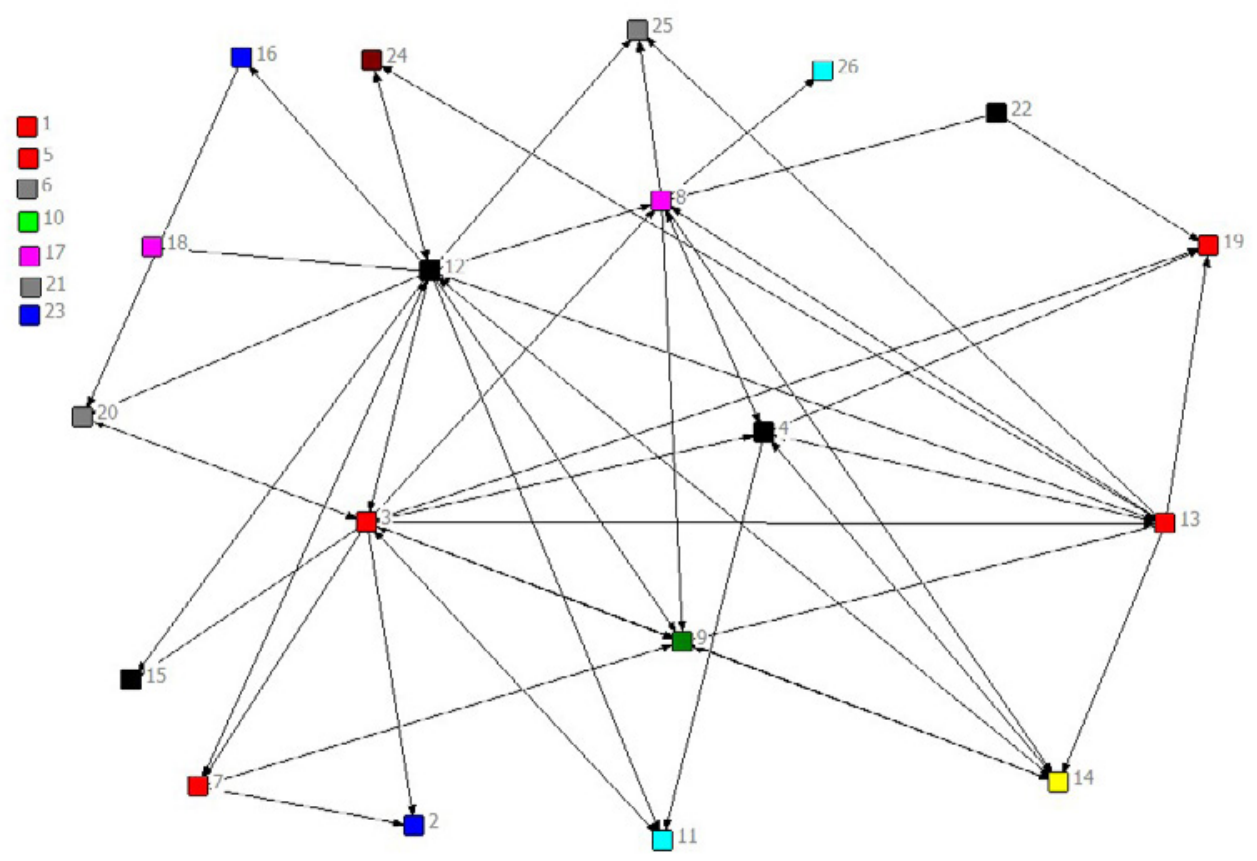

Figura 1 - Empresas que fazem negócio em conjunto Fonte: Elaborado pelos autores com base em Hanneman e Riddle (2005). 
pode resultar na sustentabilidade de sua cadeia produtiva (LÜBECK; WITTMANN; SILVA, 2012), configurando-se, portanto, como um fator facilitador para o sucesso das empresas participantes do APL.

Segundo a representante de uma prefeitura local e coordenadora do APL pesquisado, "a prefeitura tem procurado fazer ações para beneficiar as empresas, como a parceria com a Caixa com uma linha de financiamento para capital de giro, visto que a maioria das empresas são micro ou pequenas e com isso as empresas conseguiram melhorar seus negócios".

Ainda sobre essa questão, o presidente do sindicato destaca a importância da participação no APL afirmando que "o setor têxtil é o segundo setor que mais emprega e o Brasil é o quarto produtor mundial. Os EUA deixaram todas as empresas têxteis quebrarem e começaram a comprar da China e agora estão sentindo a necessidade de recomeçar", e, por conta disso, a importância do APL têxtil e de confecções situado na Grande São Paulo.

Em complemento, analisou-se a medida degree da rede formada pelas empresas do APL têxtil e de confecções, conforme Tabela 1.

Tabela 1 - Degree entre as empresas do APL (Pergunta 1)

\begin{tabular}{cccc}
\hline Actor & Indegree & Actor & Outdegree \\
\hline $1,5,6,10$, & 0 & $\begin{array}{l}1,2,5,6,9,10, \\
15,17,18,19,\end{array}$ & 0 \\
$21,22,23$ & & $\begin{array}{l}21,23,25,26 \\
11,16,20,24\end{array}$ & 1 \\
$16,18,26$ & 1 & 22 & 2 \\
$2,7,15,24$ & 2 & 7 & 3 \\
$11,13,20,25$ & 3 & 14 & 4 \\
$4,12,19$ & 4 & 8 & 5 \\
8,14 & 5 & 4 & 6 \\
3,9 & 6 & 13 & 9 \\
& & 3 & 11 \\
& & 12 & 13 \\
\hline
\end{tabular}

Fonte: Elaborado pelos autores com base na pesquisa (2015).

A Tabela 1 apresenta o grau de centralidade (degree centrality) das empresas do setor têxtil e de confecções participantes do APL de duas formas: indegree indica que a empresa (ator) é procurada para fazer negócio. Por exemplo, as empresas 1 , $5,6,10,17,21,22$ e 23 não são procuradas pelas outras empresas do APL para fazerem negócios, por esta razão o indegree é zero. Nessa rede, as empresas 3 e 9, que produzem, respectivamente, uniformes e bordados, são procuradas por outras seis empresas do APL.

O outdegree significa que a empresa procura por outra para fazer negócio. Dessa forma, as empresas 1, 2, 5, 6, 9, 10, 15, 17, 18, 19, 21, 23, 25 e 26 não procuram outras empresas do APL têxtil e de confecções para fazerem negócios. Por outro lado, a empresa 12, que produz roupas femininas, procura por outras treze empresas para fazerem negócios.

Os valores do indegree tiveram variação de 0 a 6, o que indica pouca procura por negócios entre as empresas do APL, os valores do outdegree tiveram uma variação de 0 a 13. Entretanto, catorze empresas, ou seja, mais que $50 \%$ das empresas participantes da pesquisa, não procuram por outras empresas para fazerem negócios e somente uma empresa (empresa 12) procurou por outras treze empresas para fazer negócio.

O valor da densidade é outra forma de se avaliar uma rede e de se constatar a pouca procura entre as empresas do APL para negócios. A densidade apresenta valor de 17,54\% (57 ligações entre os atores) o que significa que em $82,46 \%$ das ligações possíveis não ocorre procura para negócios.

Outra medida de centralidade é o betweenness, que demonstra entre quantos pares de empresas outra empresa serve de intermediária para fazerem negócios, conforme a Tabela 2.

Na Tabela 2, demonstrou-se que as empresas (atores) 3 e 12 estão como intermediárias para que outras empresas do APL façam negócios em mais de $50 \%$ das relações. A empresa 8 tem participação de 29,50\% nas intermediações entre as empresas para realizações de negócios. A maioria 
das empresas tem participação de menos de $25 \%$ para essas intermediações. Pode-se dizer que as empresas 3, 12 e 8 têm maior poder dentro da rede por serem as maiores intermediárias entre empresas que fazem negócios em conjunto.

Tabela 2 - Análise do betweenness no APL (Pergunta 1)

\begin{tabular}{cc}
\hline & Betweenness \\
\hline Measures & Actor \\
\hline$>50$ & 3,12 \\
$>25<=50 \%$ & 8 \\
$>5<=25 \%$ & $4,13,14,20$ \\
$>0<=5 \%$ & $1,2,5,6,7,9,10,11,15,16,17,18$, \\
& $19,21,22,23,24,25,26$ \\
\hline
\end{tabular}

Fonte: Elaborado pelos autores com base na pesquisa (2015).

A medida closeness é utilizada para verificar a centralidade e indica as empresas que estão mais "próximas" das outras com relação a fazer negócios, isto é, se há uma relação direta entre duas empresas, isso significa que elas estão próximas. Quanto maior o valor, maior é a proximidade das empresas que fazem negócios, como apresentado na Tabela 3.

Tabela 3 - Análise de closeness no APL (Pergunta 1)

\begin{tabular}{cc}
\hline \multicolumn{2}{c}{ Closeness } \\
\hline Measures & Actor \\
\hline$>5<=10 \%$ & $2,3,4,7,8,9,11,12,13,14,15,16,18$, \\
& $19,20,24,25,26$ \\
$>0<=5 \%$ & $1,5,6,10,17,21,22,23$ \\
\hline
\end{tabular}

Fonte: Elaborado pelos autores com base na pesquisa (2015)

Na Tabela 3, observou-se que, de forma geral, não há proximidade considerável entre as empresas, pois o percentual máximo foi de $7 \%$ para as empresas da primeira linha. De modo geral, as empresas estão distantes umas das outras, o que representa um fator dificultador, pois, segundo Villela e Pinto (2009), os objetivos das empresas nem sempre são comuns a todas e o processo de alinhamento demanda tempo.
A questão da troca de informações e compartilhamento de conhecimentos também é destacada por Santos et al. (2003). Para Olson (1999), a cooperação é o principal aspecto a ser considerado para a evolução e sobrevivência do APL. Foi apontado nas entrevistas pelo presidente do sindicato, pela professora de uma instituição de educação superior que colabora com o APL e a representante da prefeitura local, que há grande troca de informações entre as empresas participantes do APL, inclusive sobre a questão de mão de obra que é deficitária neste setor, porém, esta troca de informações não implica que as empresas façam negócios conjuntos com base no que elas responderam no questionário. Esse indício é justificado pelo pouco tempo de configuração do APL (dois anos) e do esperado engajamento gradativo das empresas, o que pode indicar dificuldades na governança do APL estudado.

Em relação à participação efetiva das empresas no $A P L$, a representante da prefeitura observou na reunião do arranjo, em junho de 2015, que é muito importante o comparecimento dos empresários às reuniões para fortalecimento do grupo.

Para elucidação das respostas da segunda pergunta do questionário relativa à ARS, analisou-se se as empresas ajudam/cooperam entre si, conforme a Figura 2:

Na Figura 2, observou-se que as empresas 12, 14, $16,25,26$ cooperaram com outras empresas participantes do APL, todavia, as empresas 1, 5, 6, 10, 21, 23 mantiveram-se isoladas e não cooperaram ou não receberam cooperação de outras empresas. Todas essas empresas de forma direta e indireta competem pelo mercado e um dos possíveis motivos de não estarem cooperando ou recebendo ajuda de outras empresas pode ser o não entendimento de que a união é que fortalecerá o grupo. Conforme Marcon e Moinet (2000), neste novo modelo de agrupamento de empresas que é um APL, a cooperação e a competição andam juntas, e as relações entre as empresas exercem grande influência para o sucesso do APL e, por consequência, para as próprias empresas. 


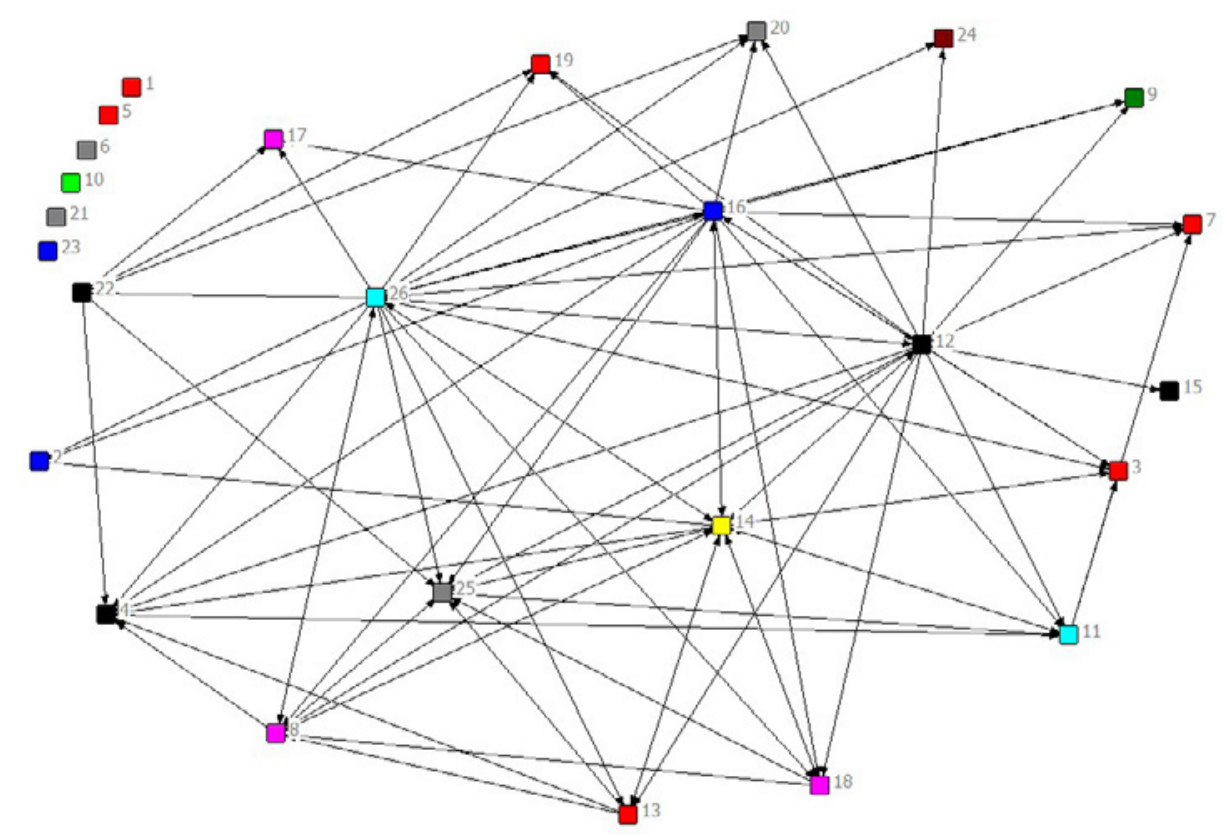

Figura 2 - Empresas que se ajudam e cooperam entre si

Fonte: Elaborada pelos autores com base em Hanneman e Riddle (2005)

Em continuidade ao estudo sobre cooperação na ARS do APL têxtil e de confecções, verificou-se a medida degree, como apresenta a Tabela 4:

Tabela 4 - Análise do degree no APL (Pergunta 2)

\begin{tabular}{cccc}
\hline Actor & Indegree & Actor & Outfegree \\
\hline $1,5,6,10,21,23$ & 0 & $\begin{array}{c}1,2,3,5,6,7,9, \\
10,15,17,19,\end{array}$ \\
\multicolumn{5}{c}{$\begin{array}{c}20,21,23,24,25 \\
15,22\end{array}$} & 1 & 4 & 1 \\
24,26 & 2 & 18 & 3 \\
$2,9,12,13$, & 3 & 8,13 & 4 \\
16,17 & & 11,22 & 5 \\
$7,11,18,19,20$ & 4 & 14 & 11 \\
3 & 5 & 16 & 14 \\
8 & 6 & 12 & 15 \\
14 & 7 & 26 & 17 \\
4 & 8 & & \\
25 & 9 & & \\
\hline
\end{tabular}

Fonte: Elaborado pelos autores com base na pesquisa (2015)

Os valores do indegree apresentados na Tabela 4 informam que as empresas 4, 8, 14, 25 recebem ajuda/cooperação de várias outras empresas em seus negócios, seja com informações sobre o mercado ou de profissionais disponíveis no mercado ou ajudas técnicas etc. As empresas 1, 5, 6, 10, 21, 23 não recebem ajuda/cooperação de outras empresas participantes do APL.

No outdegree, as empresas 11, 12, 14, 16, 22, 26 ajudam/cooperam com outras empresas do APL, entretanto, dezesseis outras empresas, o que representa $62 \%$, não ajudam/cooperam com outras empresas.

A densidade da rede relacionada com a cooperação é de 24,30\% (79 ligações entre os atores), desta forma, 75,70\% não ajudam/cooperam com empresas do APL, o que pode apontar, segundo Suzigan, Garcia e Furtado (2002 apud Sacomano Neto; Paulillo, 2012), um baixo grau de participação ou de governança no APL.

Na Tabela 5 a seguir, analisou-se a intermediação (betweenness) de uma empresa para a ajuda/ cooperação entre outras duas empresas.

A empresa 14, que produz roupas femininas e infantis, demonstrou-se como maior participante de forma direta na intermediação ajuda/cooperação entre outras empresas do grupo. As empresas $4,8,11,12,16$ e 26 também intermediaram só que em menor intensidade. As outras dezenove 
empresas apresentaram valores muito pequenos ou não participam como intermediadora na ajuda/ cooperação entre as empresas. Este resultado evidencia, respectivamente, que as empresas 14, 11 e 26 intermediam a ajuda e a cooperação de forma mais efetiva no APL e que podem exercer um papel de liderança neste.

Tabela 5 - Análise do betweenness no APL (Pergunta 2)

\begin{tabular}{cc}
\hline & Betweenness \\
\hline Measures & Actor \\
\hline$>50$ & 14 \\
$>25<=50 \%$ & 11,26 \\
$>5<=25 \%$ & $4,8,12,16$ \\
$>0<=5 \%$ & $1,2,3,5,6,7,9,10,13,15,17,18$, \\
& $19,20,21,22,23,24,25$ \\
\hline
\end{tabular}

Fonte: Elaborado pelos autores com base na pesquisa (2015)

$\mathrm{Na}$ medida closeness, quanto mais alto seu valor, mais próximas as organizações estão para ajudar/cooperar entre si, como apresentado na Tabela 6.

Tabela 6 - Análise do Closeness no APL (Pergunta 2)

\begin{tabular}{cc}
\hline \multicolumn{2}{c}{ Closeness } \\
\hline Measures & Actor \\
\hline$>5<=10 \%$ & $2,3,4,7,8,9,11,12,13,14,15,16,17$, \\
& $18,19,20,22,24,25,26$ \\
$>0<=5 \%$ & $1,5,6,10,21,23$ \\
\hline
\end{tabular}

Fonte: Elaborado pelos autores com base na pesquisa (2015)

Verificou-se, conforme a Tabela 6, que a maioria das empresas está tentando se aproximar umas das outras com o objetivo de ajudar/cooperar, mas ainda há um longo percurso para que este engajamento possa surtir resultados para o grupo, como é o caso da compra coletiva, que por enquanto é só um projeto do APL.

Ações de colaboração e cooperação também ficaram evidenciadas na reunião do APL em junho de 2015, na apresentação de projetos de cursos e desfiles feitos por instituições de educação superior junto ao arranjo, além da iniciativa já consumada da participação conjunta em feiras e bazares e também um convênio firmado entre os servidores públicos da prefeitura e as empresas que fazem parte do aglomerado para a concessão de descontos mediante compras. Resgatando o referencial teórico, Guimarães et al. (2013) apontam ações dessa natureza com benéficas na formação dos APLS.

Santos et al. (2003) também apontam que os aglomerados têm como um dos aspectos o apoio de instituições locais e do governo. A prefeitura local, cujo papel principal no APL é ser o agente coordenador, tem como objetivo trazer políticas públicas e articular os demais atores para melhorar os negócios nos municípios da região, conforme afirmou a representante da prefeitura. Turner (2001) coloca que os APLs têm uma grande importância para os atores que participam e também para a região onde se localizam e, por conta disso, a importância do apoio da prefeitura, que foi apontada nas entrevistas como um dos principais articuladores do arranjo.

Villela e Pinto (2009); Sacomano Neto e Paulillo (2012); e Suzigan, Garcia e Furtado (2002) apud Sacomano Neto e Paulillo (2012) concordam que a governança se constitui de coordenação, comando, intervenção e participação de todos do arranjo, o que fica bem claro nas entrevistas, pois todos os atores respondentes afirmaram existir uma governança participativa, na qual há destaque para o sindicato e a prefeitura. Um exemplo disso é a mediação da prefeitura em ações do APL. Segundo observado na reunião do APL em junho de 2015, um representante de uma instituição de educação superior parceira do aglomerado apresentou o projeto do desfile, no qual os empresários poderiam participar. A proposta apresentada consiste na ideia de que os alunos de um curso tecnológico promoveriam o desfile no qual seriam utilizadas roupas dos principais segmentos dos APLs (um ou dois looks por empresa). Além disso, haveria a 
possibilidade de uma empresa ser escolhida para um grupo de alunos que criaria um look exclusivo para ela. No desfile (na própria instituição de educação superior), deverá ser entregue aos empresários visitantes o catálogo do arranjo. O objetivo é que empresários de fora sejam convidados e possam fazer networking. Esta ação discutida na reunião do APL demonstra uma clara articulação entre todos os atores participantes deste.

No APL do setor têxtil e de confecções analisado, existem pessoas com conhecimento e capacitação, o que configura um sistema de governança que está se fortalecendo ao longo dos anos. A governança também tem o papel de mobilizar a coletividade. Esta função está sendo exercitada com tendência ao crescimento conforme as empresas participantes deste arranjo comecem a perceber os resultados.

\section{CONCLUSÃO}

Para o sucesso de APL, percebe-se, a partir da literatura discutida neste artigo, questões determinantes, como a cooperação real e efetiva entre os atores participantes e, sobretudo, práticas de governança eficientes geradas por fontes ligadas ao Estado, o que leva também à necessidade de criação de políticas públicas que tenham como prioridade o desenvolvimento social e econômico de regiões propensas ao surgimento de aglomerações produtivas. No entanto, o conceito de competitividade aliado à cooperação ainda encontra barreiras em sua disseminação entre os atores de um APL.

Juntas, empresas participantes de arranjos podem buscar soluções para temas específicos do setor em que se encontram como questões relativas à matéria-prima, mão de obra e acesso a clientes. No APL do setor têxtil e de confecções pesquisado, essas questões citadas são fundamentais para o desenvolvimento das empresas e do setor.
Além disso, devido à reconhecida importância dada pela literatura nos estudos sobre os aglomerados, a indicação de fatores facilitadores e dificultadores no APL do setor têxtil e de confecções, pode, ainda que de forma embrionária, contribuir para estudos em arranjos de outros setores e para o enriquecimento da literatura acadêmica na área.

A principal conclusão deste artigo é que, para o sucesso do APL estudado ainda há mais fatores dificultadores que facilitadores em suas relações. Entre eles, foi apontada pelos empresários a pouca adesão/participação das empresas do setor no arranjo, questão ratificada na reunião do APL em junho de 2015. Uma das possíveis explicações para esse fator, em se tratando especificamente do aglomerado do setor têxtil e de confecções pesquisado é seu pouco tempo de existência (cerca de dois anos). Nas respostas da pergunta 1 do questionário, que é relativa à ARS, pode-se levantar que dos 26 respondentes, apenas as empresas 3, 4, 8, 9, 12, 13, 14 e 19 se destacam como empresas que fizeram negócios com outras empresas por meio de sua participação no APL têxtil e de confecções. Em relação à pergunta 2, também concernente à ARS do arranjo, as empresas 12, 14, 16, 25, 26 cooperaram com outras empresas participantes do APL. Por outro lado, as empresas 1, 5, 6, 10, 21, 23 mantiveram-se isoladas e não cooperaram ou receberam cooperação de outras empresas.

Além disso, a falta de mão de obra especializada no setor ainda se configura como um entrave para as empresas. Esta questão foi apontada em grande parte pelas respostas da pergunta aberta do questionário, além de ter sido motivo de debate na reunião do APL do setor têxtil e de confecções e ser mencionada pelos representantes do sindicato e da prefeitura nas entrevistas concedidas para este artigo. Desta forma, a questão da mão de obra, embora pareça simples de resolver, tem se mostrado um fator dificultador ao longo dos tempos para o sucesso das empresas do APL estudado. Os 
membros participantes do APL colocam esta questão como fundamental e cobram do sindicato e da prefeitura ações mais eficazes na resolução do problema. Cursos têm sido oferecidos pelas universidades locais em parceria com as empresas. Mas há situações que são estruturais e necessitam de atenção especial, como o baixo piso salarial oferecido à mão de obra especializada no setor têxtil e de confecções e a mudança de perfil do profissional da região. Pelas respostas dos questionários, foi possível perceber que o setor têxtil e de confecções não oferece de maneira contundente ao público jovem atrativos suficientes para a renovação e capacitação da mão de obra local.

Um fator facilitador que ficou evidenciado em todos os instrumentos de pesquisa utilizados foi a tentativa de se ter práticas de governança efetiva no APL por meio da prefeitura. As ações coordenadas pela prefeitura, o contato constante com os atores e as tentativas de incentivo à participação das empresas no arranjo são apontadas como práticas que fomentam o crescimento do APL e fazem com que a comunicação entre os membros seja facilitada, apesar das dificuldades existentes.

\section{REFERÊNCIAS}

AMARAL, M. E. M. Vantagem competitiva de empresas localizadas em arranjos produtivos locais: um estudo teórico. In: CONGRESSO NACIONAL DE EXCELÊNCIA EM GESTÃO, 9., 2013, Rio de Janeiro. Anais... Rio de Janeiro: Inovarse, 2013. Disponível em: <http://bit. ly/2nM8ZVt>. Acesso em: 7 abr. 2017.

ANTERO, C. A. S. et al. Coordination of Joint Actions in Muriaé's (MG) Clothing LPA. Revista de Administração Mackenzie, São Paulo, v. 17, n. 3, p. 158-182, 2016.

BRITO, E. P. Z. et al. Arranjos produtivos locais e crescimento. In: ENCONTRO DA ASSOCIAÇÃO NACIONAL DE PÓS-GRADUAÇÃO E PESQUISA EM ADMINISTRAÇÃO, 2008. Rio de Janeiro. Anais... Rio de Janeiro: Anpad, 2008.

CASSANEGO, J. P. V. Governança em clusters de negócios: um estudo em clusters do Rio Grande do Sul. Tese (Doutorado em Ciências) - Faculdade de Economia, Administração e Contabilidade, Universidade de São Paulo, São Paulo, 2014.

CASSIOLATO, J. E; LASTRES, H. O foco em arranjos produtivos e inovativos locais de micro e pequenas empresas. In: CASSIOLATO, J. E.; LASTRES, H.; MACIEL, M. L (Orgs.). Systems of innovation and development: evidence from Brazil. Cheltenham, RU: Edward Elgar, 2003.

CASSIOLATO, J. E.; SZAPIRO, M. Uma caracterização de arranjos produtivos locais de micro e pequenas empresas. In: LASTRES, H.; CASSIOLATO, J. E.; MACIEL, M. L. M. (Orgs.). Pequena empresa: cooperação e desenvolvimento local. Rio de Janeiro: Relume Dumará, 2003.

CASTELLS, M. A sociedade em rede. 11. ed. São Paulo: Paz e Terra, 1999.

COSTA, M. T. As pequenas e médias firmas no desenvolvimento local: conceito e experiências. In: GUIMARÃES, N. A.; MARTIN, S. (Orgs.). Competitividade e desenvolvimento: atores e instituições locais. São Paulo: Senac, 2001.

COSTA, S. N.; RABELO, R. J. Uma proposta de modelo de governança para empresas virtuais. In: SIMPÓSIO DE ADMINISTRAÇÃO DA PRODUÇÃO, LOGÍSTICA E OPERAÇÕES INTERNACIONAIS, 16., 2013, São Paulo. Anais... São Paulo: FGV, 2013. 


\section{REFERÊNCIAS}

CRESWELL, J. W. Projeto de pesquisa: métodos qualitativos, quantitativos e misto. 2. ed. Porto Alegre: Artmed, 2007.

CRUZ, J. A. W.; MARTINS, T. S.; QUANDT. C. O. Redes de cooperação: um enfoque de governança. Revista Alcance, Itajaí, v. 15, n. 2, p.190-208, 2008.

DONAIRE, D. et al. Competitividade de clusters comerciais: estudo sobre uma aglomeração de pequenas lojas de veículos no município de São Paulo. Revista da Micro e Pequena Empresa, São Paulo, v. 7, n. 3, p. 6478, 2013.

GIL, A. C. Como elaborar projetos de pesquisa. 4. ed. São Paulo: Atlas, 2002.

GUIMARÃES, A. T. R. Empresas instaladas em clusters com orientação estratégica dual, originadas na governança de clusters e de redes de negócios: uma busca focada no negócio do vinho das regiões do Porto, em Portugal e do vale dos vinhedos, no Brasil. Tese (Doutorado em Administração) - Faculdade de Economia e Administração, Universidade de São Paulo, São Paulo, 2010.

GUIMARÃES, A. T. R. et al. Empresas instaladas em clusters com orientações estratégicas duais influenciadas pelas governanças supra-empresariais de clusters e de redes de negócios: um estudo do setor de vitivinicultura no Brasil e Portugal. In: ENCONTRO DA ASSOCIAÇÃO NACIONAL DE PÓSGRADUAÇÃO E PESQUISA EM ADMINISTRAÇÃO, 37., 2013, Rio de Janeiro. Anais... Rio de Janeiro: Anpad, 2013.

HANNEMAN, R. A.; RIDDLE, M. Introduction to social network methods. Riverside, CA: University of California, 2005. Disponível em: <http://bit.ly/1 pBOWWg>. Acesso em: 14 jun. 2015.
HITT, M. A.; IRELAND, R. D; HOSKISSON, R. E. Administração estratégica: competitividade e globalização. São Paulo: Thomson Learning, 2013.

KNOKE, D.; YANG, S. Social network analysis. London: Sage, 2008.

LASTRES, H. M. M.; CASSIOLATO, J. E. Glossário de arranjos e sistemas produtivos e inovativos locais. Rio de Janeiro: UFRJ, 2003. Disponível em: <http://bit. ly/2oVS185>. Acesso em: 15 mar. 2015.

LÜBECK, R. M.; WITTMANN, M. L.; SILVA, M. S. Afinal, quais variáveis caracterizam a existência de cluster arranjos produtivos locais (APLS) e dos sistemas locais de produção e inovação (SLPIS)? Revista IberoAmericana de Estratégia, São Paulo, v. 11, n. 1, p. 120151, 2012.

MACEDO, R. A.; ARAÚJO, L. J. S.; CAMPOS, A. L. S. Clusters de pequenas e médias empresas e desenvolvimento regional. Revista Eletrônica Gestão e Serviços, São Paulo, v. 5, n. 2, p. 1014-1032, 2014.

MARCON, C.; MOINET, N. Estratégia-rede: ensaio de estratégia. Caxias do Sul: Educs, 2000.

MARTELETO, R. M. Análise de redes sociais - aplicação nos estudos de transferência da informação. Ciência da Informação, Rio de Janeiro, v. 30, n. 1, p. 71-81, 2001.

MASQUIETTO, C. D.; SACOMANO NETO, M.; GIULIANI, A. C. Identificação de arranjos produtivos locais: o caso do arranjo produtivo local do álcool de Piracicaba. Gestão \& Regionalidade, São Paulo, v. 26, n. 77, p. 7587, 2010.

MIZRUCHI, M. S. Análise de redes sociais: avanços recentes e controvérsias atuais. Revista de Administração de Empresas, São Paulo, v. 46, n. 3, p. 72-86, 2006. 


\section{REFERÊNCIAS}

NEWMAN, M. E. J. Networks an introduction. Oxford: Oxford University Press, 2010.

OLIVEIRA, C. M.; SANTANA, A. C. Competitividade das empresas no arranjo produtivo: local de grãos em Santarém e Belterra/Pará. Desenvolvimento em Questão, ljuí, v. 14, n. 34, p. 351-382, 2016.

OLSON, M. A lógica da ação coletiva: os benefícios públicos e uma teoria dos grupos sociais. São Paulo: Edusp, 1999. 459 p.

PARKHE, A.; WASSERMAN, S.; RALSTON, D. A. New frontiers in network theory development. Academy of Management Review, New York, v. 31, n. 3, p. 560-568, 2006.

PATIAS, T. Z. et al. Uma análise do capital social no arranjo produtivo local do leite de Santana do Livramento. Desenvolvimento em Questão, ljuí, v. 13, n. 30, p. 175202, 2015.

PIGATTO, G. et al. Redes sociais de produtores de mandioca em regiões do estado de São Paulo. Interações, Campo Grande, v. 16, n. 1, p. 75-86, 2015. Disponível em: <http://bit.ly/2o3egf9>. Acesso em: 29 maio 2017.

PORTER, M. Clusters and the new economics of competition. Harvard Business Review, Cambridge, p. 77-90, nov./dec. 1998.

RUFFONI, J.; SUZIGAN, W. Comportamento de firmas industriais em fluxos de conhecimento: uma análise para dois aglomerados produtivos. Estudos Econômicos, São Paulo, v. 45, n. 4, p. 693-724, 2015. Disponível em: <http://bit.ly/2ouZkqK>. Acesso em: jul 2016.

SACOMANO NETO, M.; PAULILLO, L. F. O. Estruturas de governança em arranjos produtivos locais: um estudo comparativo nos arranjos calçadistas e sucroalcooleiros no estado de São Paulo. Revista Administração Pública, Rio de Janeiro, n. 46, v. 4, p. 1131-155, 2012.

SANTOS F.; CROCCO, M.; SIMÕES, R. Arranjos produtivos locais informais: uma análise de componentes principais para Nova Serrana e Ubá, Minas Gerais. Ensaios FEE, Porto Alegre, v. 24, n. 1, p. 177-202, 2003.

SANTOS, L. G. A.; ROSSONI, L.; MACHADO-DA-SILVA, C. L. Condicionantes estruturais dos relacionamentos intraorganizacionais: uma análise da influência sobre relações de comunicação e decisão. Revista de Administração Mackenzie, São Paulo, v. 12, n. 1, p. 139168, 2011. Disponível em: <http://bit.ly/2oCGOtA>. Acesso em: 29 maio 2017.

SCHMITZ, H.; NADVI, K. Clustering and industrialization: introduction. World Development, London, v. 27, n. 9, p. 1503-1514, 1999.

SCOTT, J. Social network analysis: a handbook. London: Sage, 2009.

SOUSA, A. R. et al. Cooperação no APL de Santa Rita do Sapucaí. Revista de Administração Mackenzie, São Paulo, v. 16, n. 1, p. 157-187, 2015.

TEIXEIRA, F. Políticas públicas para o desenvolvimento regional e local: o que podemos aprender com os arranjos produtivos locais (APLs)? Organizações \& Sociedade, Salvador, v. 15, n. 46, 2009. Disponível em: <http://bit.ly/2nCmMi3>. Acesso em: 29 maio 2017.

TOLEDO, M. M.; GUIMARÃES, L. O. Concentração locacional: confecções mineiras em foco. Revista Brasileira de Gestão de Negócios, São Paulo, v. 10, n. 27, p. 189-205, 2008. 


\section{REFERÊNCIAS}

TURNER, R. C. A framework for cluster based economic development policies. New York: The Nelson A. Rockefeller Institute of Government, 2001.

VILLELA, L. E.; PINTO, M. C. S. Governança e gestão social em redes empresariais: análise de três arranjos produtivos locais (APLs) de confecções no estado do Rio de Janeiro. Revista de Administração Pública, Rio de Janeiro, n. 43, v. 5, p. 1067-1089, 2009.

WASSERMAN, S.; FAUST, K. Social network analysis: methods and applications. New York: Cambridge Press, 1999.
WELLMAN, B. Network analysis: from method and metaphor to theory and substance. In: WELLMAN, B.; BERKOWITZ, S. D. (Eds.). Social structures: a network approach. New York: Cambridge University Press, 1988.

WITTMANN, M. L.; RAMOS, M. P. Desenvolvimento regional: capital social, redes e planejamento. Santa Cruz do Sul: Edunisc, 2004.

ZACCARELLI, S. B. et al. Clusters e redes de negócios: uma nova visão para a gestão dos negócios. São Paulo: Atlas, 2008. 